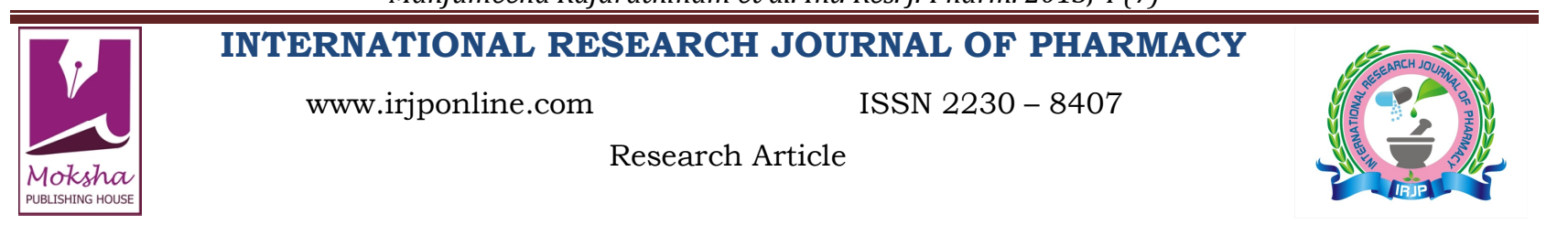

\title{
BIOGENIC NANOSILVER AS A POTENTIAL ANTIBACTERIAL AND ANTIFUNGAL ADDITIVE TO COMMERCIALLY AVAILABLE DISH WASH AND HAND WASH FOR AN ENHANCED ANTIBACTERIAL AND ANTIFUNGAL ACTIVITY AGAINST SELECTED PATHOGENIC STRAINS
} Manjumeena Rajarathinam*, P. T. Kalaichelvan

CAS in Botany, University of Madras, Guindy Campus, Chennai, India *Corresponding Author Email: manjumeena1989@gmail.com

Article Received on: 19/05/13 Revised on: 07/06/13 Approved for publication: 01/07/13

DOI: $10.7897 / 2230-8407.04715$

IRJP is an official publication of Moksha Publishing House. Website: www.mokshaph.com

(C) All rights reserved.

\section{ABSTRACT}

In the present study, biogenic silver nanoparticles rapidly synthesized using leaf extract of Rosa indica-wichuriana hybrid Francois guillot were investigated for their potential use as a antibacterial and antifungal additive to commercially available dish wash and hand wash. UV-vis spectrophotometer, Powder X-ray diffraction, FTIR spectroscopy, HrTEM and EDX analysis were used to characterize the synthesized silver nanoparticles. UV-vis spectrum analysis showed the surface plasmon peak at $427 \mathrm{~nm}$. From high resolution transmission electron microscopy (HrTEM) analysis, the size of the silver nanoparticles was determined to be $15-25 \mathrm{~nm}$. The synergy of biogenic silver nanoparticles and commercially available dish wash and hand wash showed enhanced antibacterial and antifungal activity against selected pathogenic strains Escherichia coli, Staphylococcus aureus, Micrococcus luteus, Klebsiella pneumoniae, Candida albicans, C. tropicalis, C. krusei.

Keywords: Antibacterial, Antifungal, Additive, Biosynthesis, Silver nanoparticles, Rosa indica

\section{INTRODUCTION}

In recent years, development of consumer goods using nanosized silver and its derivatives has attracted great attention due to their strong antimicrobial properties compared to those goods with bulk silver materials. A rapid increase in microbes that are resistant to conventional antibiotics has been observed ${ }^{1}$. Elemental silver and silver salts have been extensively employed as antimicrobial agents in curative and preventive health care from time immemorial, even before the advent of synthetically manufactured organic medicines such as penicillin ${ }^{2}$. As the increase in the number of antibiotic-resistant bacterial strains is of growing concern in public health care, silver nanoparticles as an antimicrobial agent are gaining great demand in medical applications ${ }^{3,4}$. Nanomaterials are at the leading edge of the rapidly developing field of nanotechnology. Their unique size dependent properties make these materials superior and indispensable in many areas of human activity ${ }^{5}$. As antibacterial agents, AgNPs are applied in a wide range of applications from disinfecting medical devices and home appliances to water treatment ${ }^{6,7}$. Silver nanoparticles are of considerable interest owing to their distinct electrical, electronic, thermal, optical, magnetic, catalytic, sensing and antimicrobial functionalities compared to bulk metal ${ }^{8}$. These properties are related to physical properties such as size, shape and inter-particle spacing 9 . In addition, silver is known to exhibit oligodynamic effect because of its ability to exert bactericidal activity at minute concentrations ${ }^{10}$. The development of resistance to silver in microbes is improbable due to its action on a broad spectrum of targets in the cell ${ }^{11}$. The advantage of silver nanoparticles compared to bulk metal or salts is the slow and regulated release of silver from nanoparticles thereby causing long lasting protection against microbes $^{12}$. Fungal infections have become more common in the recent years and silver nanoparticles have emerged as potential anti fungal agents. In particular, fungal infections are most commonly found in immune compromised patients because of cancer chemotherapy or human immunodeficiency viral infections ${ }^{13}$. Especially, the frequency of infections provoked by opportunistic fungal strains has increased drastically. Several researchers have made attempts to synthesis AgNPs using chemical reduction, electrochemical reduction and photochemical reduction. These methods employ harsh reducing and stabilizing agents making these methods unsuitable for biological applications. To overcome the drawbacks of chemical reduction, electrochemical reduction and photochemical reduction ${ }^{14,15}$ for the synthesis of AgNPs the interest has shifted towards 'green' chemistry and bioprocess approach. These approaches focus on the utilization of environment friendly, cost effective and biocompatible reducing agents. These agents give sufficient stability under strong electrolytic and $\mathrm{pH}$ condition for therapeutic application ${ }^{16}$. There are several reports which describe the use of natural material sources like plants ${ }^{17-19}$, bacteria $^{20}$, fungi ${ }^{21}$, yeast ${ }^{22}$, for synthesizing gold and silver nanoparticles. However, Plant-based nanoparticle syntheses can be advantageous over these other biological methods as the reaction rate for the synthesis of nanoparticles is very high and there is no need to grow microbes ${ }^{23}$. Furthermore, plant extracts can also be scaled up for large-scale production of $\mathrm{NP}^{24}$. With the increase in resistance of microorganisms multiple antibiotics and the emphasis on health care costs, many researchers have tried to develop new, effective antimicrobial agents, free of resistance and cost-effective. These factors have led to the resurgence in the use of silver-based antiseptics that may be linked to broad-spectrum activity and far lower propensity to induce microbial resistance than antibiotics ${ }^{25}$. In the present study, biogenic silver nanoparticles synthesized using the leaves of Rosa indica - wichuriana hybrid Francois guillot (Figure 1) are evaluated as a promising antibacterial and antifungal additive to commercially available dish wash and hand wash for an enhanced antibacterial and antifungal activity of the dish wash and hand wash. 


\section{MATERIALSAND METHODS}

\section{Chemicals}

Silver nitrate (Merck Darmstadt, Germany), potassium dihydrogen phosphate, dipotassium hydrogen phosphate, magnesium sulfate heptahydrate and ammonium sulphate (SRL Mumbai, India), glucose (Rankem Mumbai, India) and Muller-Hinton agar (Himedia Mumbai, India) were used.

\section{Source of Microorganisms}

Pure cultures of Bacteria Escherichia coli (ATCC 8739), Staphylococcus aureus (ATCC 6538), Micrococcus luteus (ATCC 4698), and Klebsiella pneumoniae (ATCC 13883) were obtained from American Type Culture Collection. The strains Candida albicans, C. tropicalis, C. krusei were obtained from VHS hospital, Chennai, India.

\section{Preparation of leaf extract}

Aqueous extract of Rosa indica - wichuriana hybrid Francois guillot (Figure 2 inset- a) was prepared using freshly collected leaves $(10 \mathrm{~g})$. Leaves were surface cleaned with running tap water, followed by distilled water and boiled with $100 \mathrm{ml}$ of distilled water at $60^{\circ} \mathrm{C}$ for 5 minutes. This extract was filtered through a nylon mesh, followed by Millipore filter $(0.45 \mu \mathrm{m})$. Filtered leaf extract was stored at $-4{ }^{\circ} \mathrm{C}$ for further use, usable for 1 week.

\section{Synthesis of silver nanoparticles}

For synthesis of silver nanoparticles, $1 \mathrm{~mL}$ of $10 \mathrm{mM}$ $\mathrm{AgNO}_{3}$ was added to $9 \mathrm{~mL}$ of the aqueous extract of Rosa indica - wichuriana hybrid Francois guillot leaves. This setup was incubated in dark at $37^{\circ} \mathrm{C}$ under static condition. The solution turned brown in color within 20 minutes (Figure 2 inset- $b$ ) indicating the synthesis of AgNPs. A control setup was also maintained without leaves extract.

\section{Characterization of the synthesized nanoparticles}

After the synthesis process was completed by reducing metal ion solution with leaves extract, Surface plasmon resonance of silver nanoparticles was easily confirmed by UV-vis spectroscopy. The reaction mixture was sampled at regular intervals and the absorption maxima was scanned at the wavelength of 400-800 $\mathrm{nm}$ in UNICAM UV 300 spectrophotometer. The biologically synthesized AgNPs gave sharp peak in the visible region of the electromagnetic spectrum. The X-ray powder diffraction data was acquired by PAN analytical X'Pert PRO diffractometer in BraggBrentano geometry using step scan technique and Johansson monochromator to produce pure $\mathrm{Cu} \mathrm{K \alpha 1}$ radiation (1.5406 $\AA$; $45 \mathrm{kV}, 30 \mathrm{~mA}$ ) in the range of $20^{\circ}-90^{\circ}$. The peaks were matched with JCPDF Card No-087-0720. The obtained pattern was for fcc cubic crystal structure. The peak plane matched with the card. The crystalline size was calculated from the full-width at half-maximum (FWHM) of the diffraction peaks using the Debye-Sherrer formula$$
\mathrm{D}=0.89 \lambda / \quad \beta \cos \theta
$$

where, $\mathrm{D}$ is the mean grain size, $\lambda$ is the $\mathrm{X}$-ray wavelength for $\mathrm{Cu}$ target, $\beta$ is the FWHM of diffraction peak and $\theta$ is the diffraction angle
}

In order to measure the size of nanoparticles accurately each peak is Gaussian fitted and also the instrumental broadening is subtracted using Si standard sample broadening. The FT-
IR spectra for biologically synthesized AgNPs, commercially available dish wash, hand wash and their combination with AgNPs were recorded on a IR Affinity-1 SHIMADZU spectrophotometer in transmittance mode in the range of 400$4000 \mathrm{~cm}^{-1}$ at a resolution of $4 \mathrm{~cm}^{-1}$. For High resolution transmission electron microscope (HrTEM) measurements, a drop of solution containing synthesized silver nanoparticles was placed on the carbon coated grids and kept under vacuum desiccation over night before loading them onto a specimen holder. HrTEM micrographs were taken by analyzing the prepared grids on $300 \mathrm{kv}$ field emission TEMSTEM (FEI F30) with capability of HAADF, EELS and EDX.

Evaluation of biogenic AgNPs as a potential antibacterial and antifungal additive to commercially available dish wash and hand wash

The biosynthesized AgNPs were used as antibacterial and antifungal additive to commercially available dish wash and hand wash by using a formulation of 5 vol.\% of the AgNps related to dish wash and hand wash volume ${ }^{26}$. Homogeneous mixing of the sample with the biosynthesized AgNPs was brought about by stirring with a glass rod for 15 minutes and kept overnight at room temperature. The antibacterial and antifungal activity of the biosynthesized AgNPs, commercially available dish wash, hand wash and their combination with AgNPs against test strains (Bacteria Escherichia coli, Staphylococcus. aureus, Micrococcus luteus, Klebsiella pneumoniae. Fungi- Candida albicans, $C$. tropicalis, C. krusei) were investigated by the micro-dilution method $^{27}$. The cultures were inoculated from fresh colonies on agar plates into $100 \mathrm{~mL}$ Muller Hinton culture medium. The cultures were allowed to grow until the optical density reached 0.2 at $600 \mathrm{~nm}$ (OD of 0.2 corresponding to a concentration of $10^{8} \mathrm{CFUmL}^{-1}$ of medium). Various dilutions of silver nanoparticles, were added to the bacterial and fungal culture (individually) in the 96 well micro-titer plate in a sequence and immediately after inoculation, the micro-titer plate was covered with a clear tape to prevent the culture medium from drying out. The inoculated micro-titer plates were incubated at room temperature for $24 \mathrm{~h}$ (bacteria) and $48 \mathrm{~h}$ (fungi) in the shaker to maintain uniformity in the growth of the microbes. After the incubation the absorbance of the sample was measured at the wavelength of $600 \mathrm{~nm}$ in the ELISA plate reader Biotek, power wave XS.

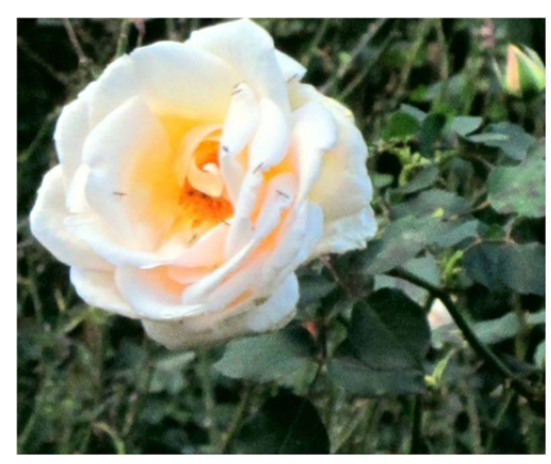

Figure 1: Rosa indica-Wichuriana hybrid Francois guillot leaves with a flower 


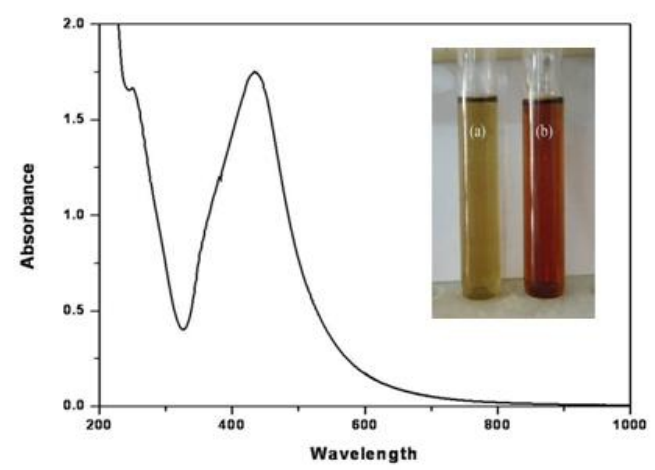

Figure 2: UV-Vis spectrum of the biologically synthesized silver nanoparticles after the reaction with aqueous silver nitrate and leaf extract. Inset: Test tubes with (a) Rosa indica-Wichuriana hybrid Francois guillot leaf extract (b) synthesized silver nanoparticles

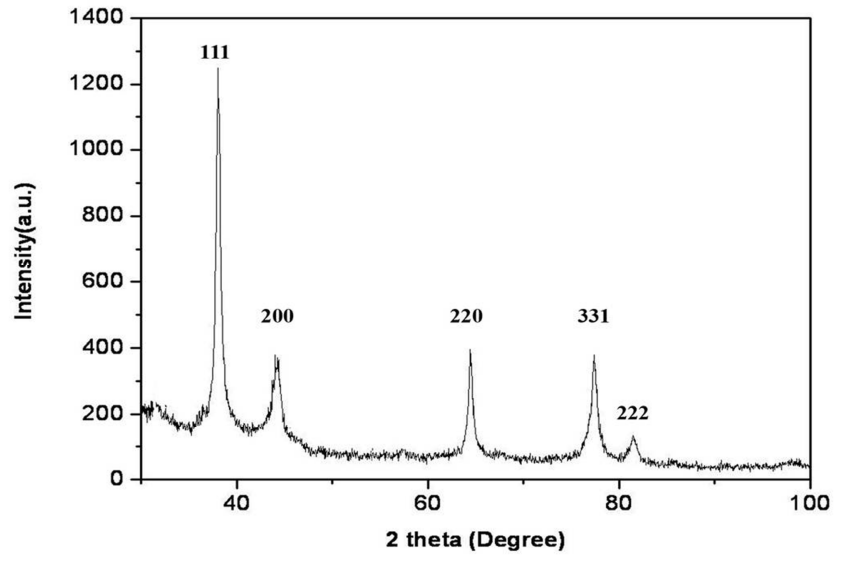

Figure 3: XRD pattern of silver nanoparticles with lattice planes

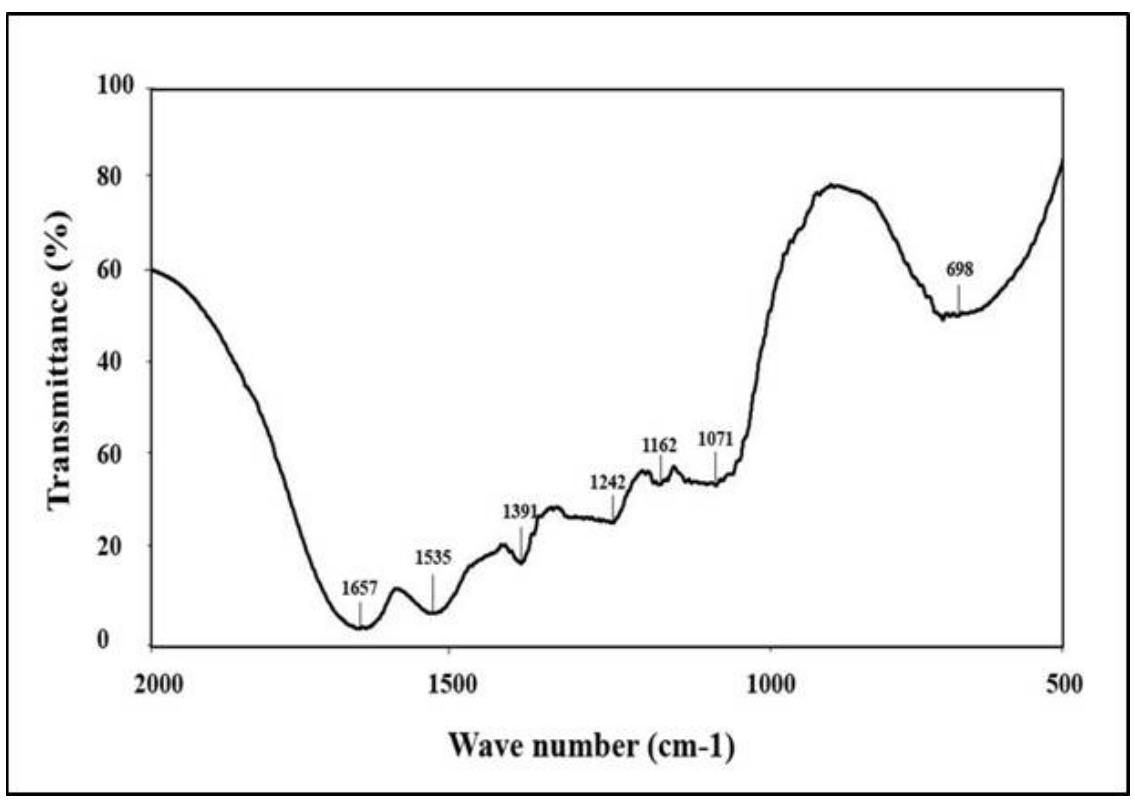

Figure 4: FTIR spectrum of the biosynthesized AgNPs 

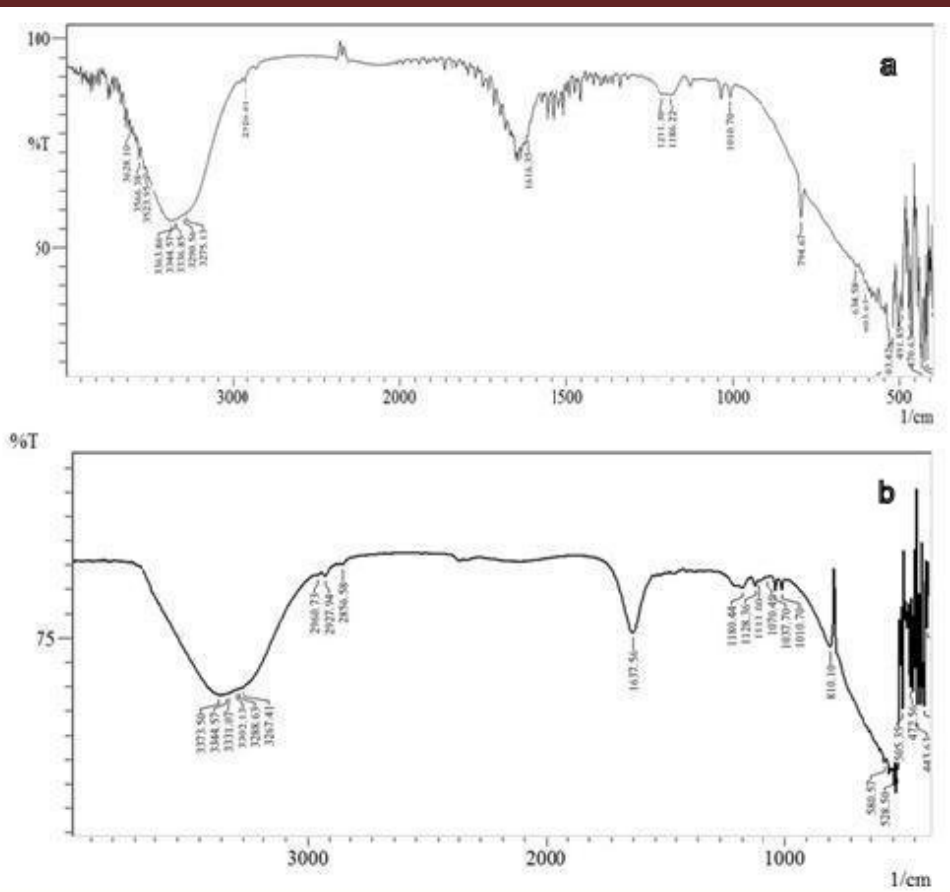

Figure 5: (a) FTIR spectrum of commercially available dish wash

(b) FTIR spectrum of biologically synthesized AgNPs incorporated commercially available dish wash
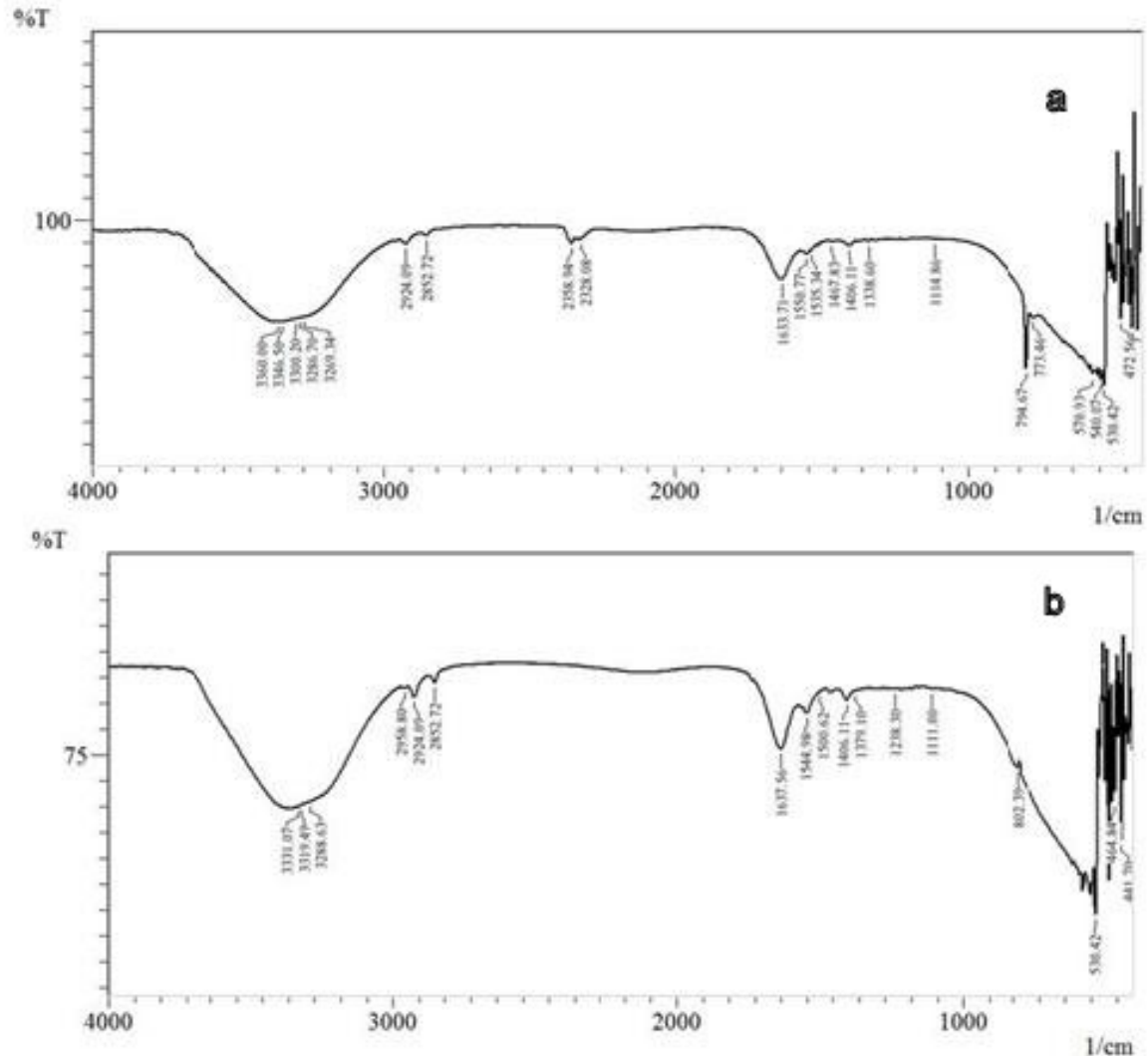

Figure 6: (a) FTIR spectrum of commercially available hand wash

(b) FTIR spectrum of biologically synthesized AgNPs incorporated commercially available hand wash 


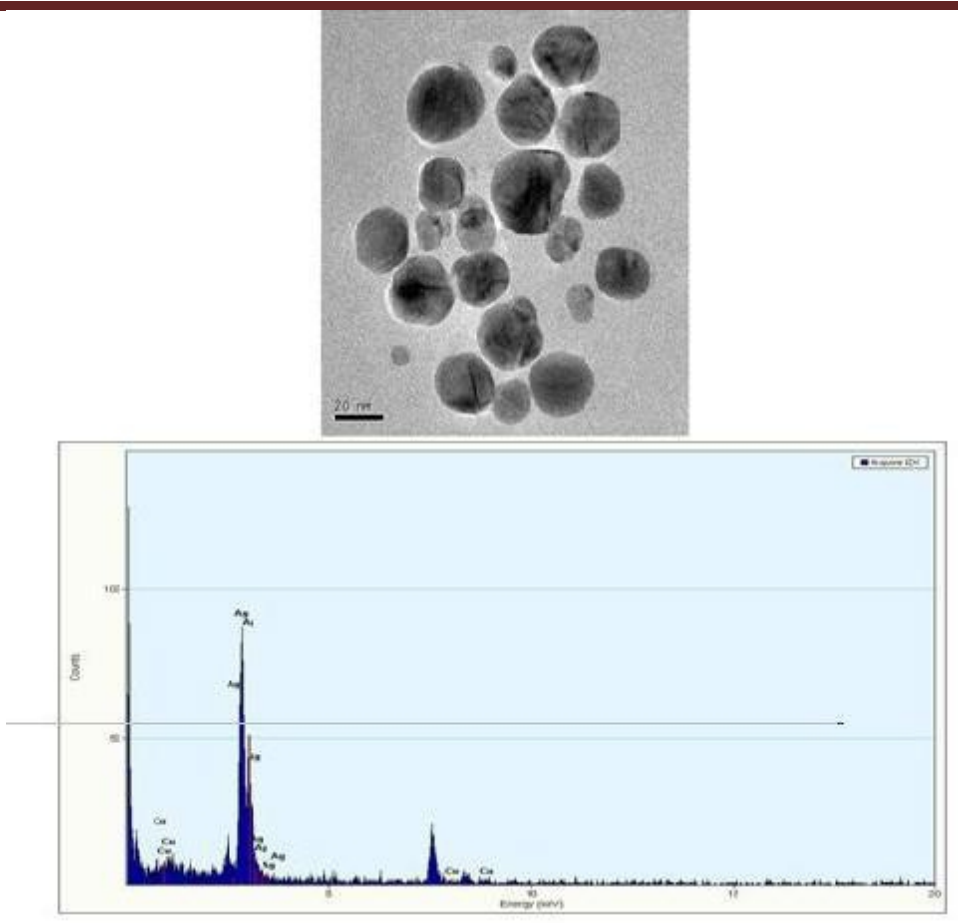

Figure 7: HrTEM micrograph of biologically synthesized AgNPs (Top) EDS spectrum of silver nanoparticles (Bottom)
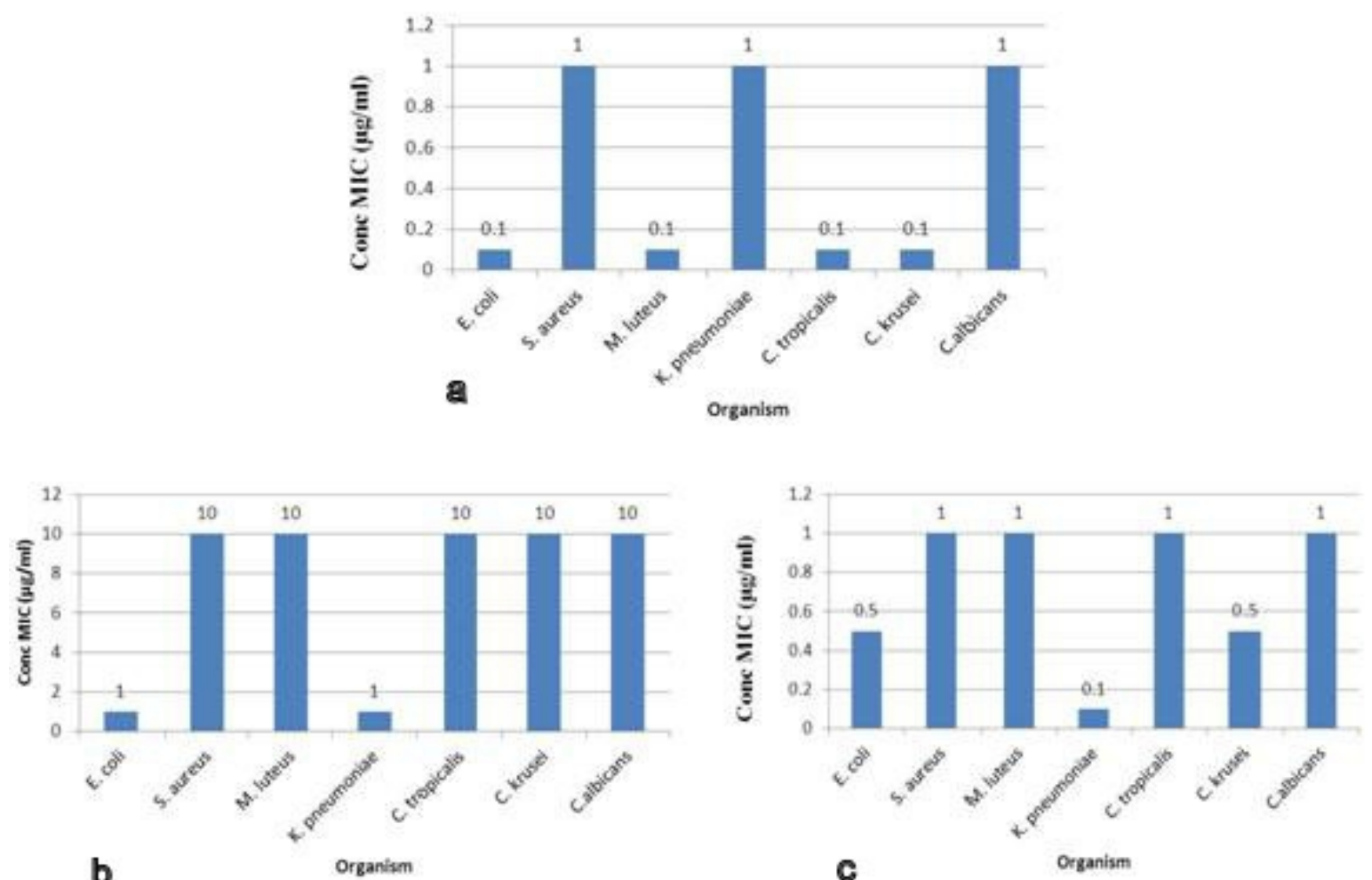

Figure 8: (a) MIC of biologically synthesized AgNPs against selected pathogenic bacterial and fungal strains (b) MIC of commercially available dish wash against selected pathogenic bacterial and fungal strains

(c) MIC of biologically synthesized AgNPs incorporated commercially available dish wash against selected pathogenic bacterial and fungal strains 

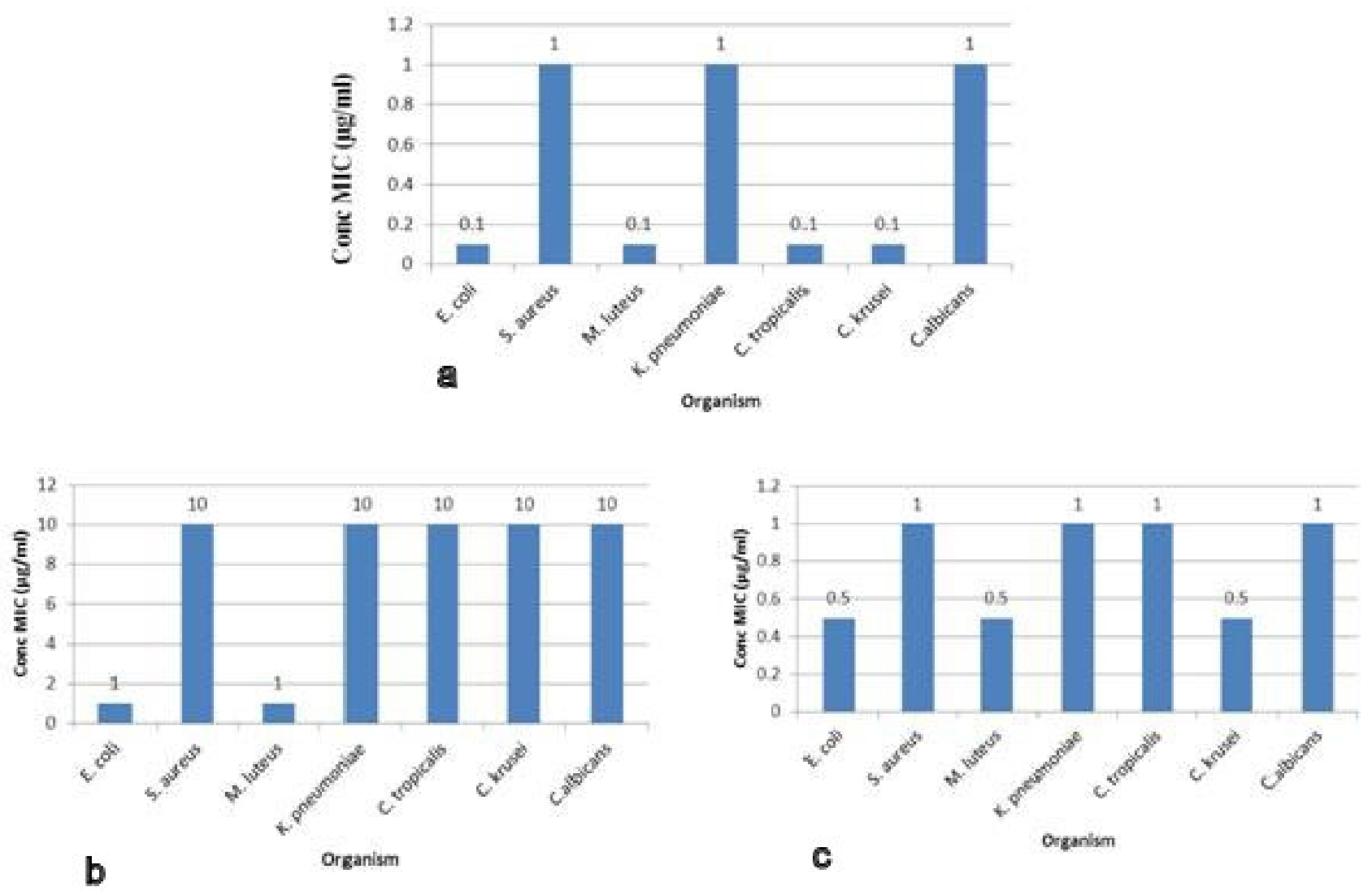

Figure 9: (a) MIC of biologically synthesized AgNPs against selected pathogenic bacterial and fungal strains (b) MIC of commercially available hand wash against selected pathogenic bacterial and fungal strains

(c) MIC of biologically synthesized AgNPs incorporated commercially available hand wash against selected pathogenic bacterial and fungal strains

\section{RESULTS AND DISCUSSION}

\section{UV-vis spectra analysis}

UV-vis spectroscopy is an important technique to ascertain the formation and stability of metal nanoparticles in aqueous solution. Figure 2 shows a characteristic surface plasmon resonance band for synthesized AgNPs, centred at $427 \mathrm{~nm}$. Intensity of brown color increased in direct proportion to the incubation period. It may be due to the excitation of surface plasmon resonance (SPR) effect and reduction of $\mathrm{AgNO}_{3}{ }^{28}$. Metal nanoparticles such as silver have free electrons, which give rise to surface plasmon resonance (SPR) absorption band $^{29}$. This result implies that the AgNPs prepared by green synthesis method is very stable without aggregation. The stability results from a potential barrier that develops as a result of the competition between weak Vander Waals forces of attraction and electrostatic repulsion ${ }^{30}$. The solution was stable even after 120 days of reaction, with no evidence of aggregation of particles.

\section{Powder X-ray diffraction}

The crystalline nature of AgNPs was confirmed from X-ray diffraction (XRD) analysis. Figure 3 shows the XRD pattern of the synthesized AgNPs. The five diffraction peaks were observed at $38.2^{\circ}, 44.4^{\circ}, 64.6^{\circ}, 77.6^{\circ}, 81.7^{\circ}$ in the $2 \theta$ range can be indexed to the (111) (200) (220) (331) and (222) reflection planes of face centred cubic structure of metallic silver nanopowders. The mean size of the biosynthesized silver nanoparticles was determined to be in the range of 18$20 \mathrm{~nm}$. The calculated lattice parameter was found to be 4.08 A.

\section{FTIR spectroscopy}

FTIR measurements were used to identify the possible biomolecules responsible for reduction and stabilization of the AgNPs. The AgNPs were stabilized in the solution by capping agents which are likely to be proteins present in the leaves extract. Figure 4 shows the FTIR spectrum of the synthesized AgNPs. The spectrum shows the presence of bands at 1657, 1535, 1391, 1242, 1162, 1071 and $698 \mathrm{~cm}^{-1}$. The strong absorption bands observed at 1657 and $1535 \mathrm{~cm}^{-1}$, are characteristic for amide I and $1071 \mathrm{~cm}^{-1}$ for amide-II, respectively ${ }^{31}$. The positions of these bands were almost similar to that reported for native proteins ${ }^{32}$. The band approximately at $1391 \mathrm{~cm}^{-1}$ is assigned to the methylene scissoring vibration from the proteins. The FTIR result indicates that the secondary structures of proteins were not affected by the reaction with $\mathrm{Ag}^{+}$ions or binding with $\mathrm{AgNPs}^{21}$. Figure 5 and 6 show the FTIR spectrum of dish wash, hand wash individually and their combination with AgNPs. The spectrum of AgNPs incorporated dish wash 
shows the disappearance of bands at $3628 \mathrm{~cm}^{-1}$ and 1616 $\mathrm{cm}^{-1}$ which correspond to secondary alcohol $\mathrm{OH}$ stretch and primary amine $\mathrm{NH}$ bend respectively and appearance of new band at $1637 \mathrm{~cm}^{-1}$ which corresponds to alkenyl $\mathrm{C}=\mathrm{C}$ stretch when compared to the spectrum of dish wash individually. Similarly, the spectrum of AgNPs incorporated hand wash shows the disappearance of bands at $3360 \mathrm{~cm}^{-1}, 3346 \mathrm{~cm}^{-1}$, $2358 \mathrm{~cm}^{-1}$, which correspond to aliphatic secondary amine NH stretch, aliphatic primary amine NH stretch, nitriles respectively and appearance of new bands at $1544 \mathrm{~cm}^{-1}, 1238$ $\mathrm{cm}^{-1}$ which correspond to aliphatic nitro compounds and skeletal C-C vibrations respectively when compared to the spectrum of hand wash individually.

\section{HR-TEM and EDX analysis}

The HrTEM technique was used to visualize the size and shape of the synthesized silver nanoparticles. Figure 7 (Top) shows the typical bright field HrTEM micrograph of the synthesized silver nanoparticles. The observed morphology of nanoparticles in the micrograph is spherical. The HrTEM micrograph suggests that the size of the particles is around 15-25 nm. In EDX analysis, Figure 7 (Bottom) shows the peak in silver region which confirms the presence of elemental silver, indicating the reduction of silver ions to elemental silver. The peak was observed approximately at 3 $\mathrm{KeV}$, typical for the absorption of metallic silver nanocrystallites $^{33}$.

\section{Evaluation of biogenic AgNPs as a potential antibacterial and antifungal additive to commercially available dish wash and hand wash}

The minimum inhibitory concentrations (MIC) of the synthesized AgNPs, commercially available dish wash, hand wash and their combination with AgNPs against test bacterial and fungal strains were determined and compared as shown in Figure 8 and 9. The results showed that the MIC for test bacterial and fungal strains decreased considerably after incorporating the biosynthesized AgNPs with dish wash and hand wash when compared to the MIC of AgNPs, dish wash and hand wash separately. According to the reports of Kim et $a l$, silver nanoparticles exhibited excellent anti fungal activity on Candida albicans by disrupting the cell membrane and inhibiting the normal budding process ${ }^{34}$. Antifungal activity is due to the formation of insoluble compounds by inactivation of sulfhydryl groups in the fungal cell wall and disruption of membrane bound enzymes and lipids which causes cell lysis ${ }^{35}$. Yamanaka and co workers suggested that the initial mode of bacterial inactivation was via damage to the wall and cellular membrane, leading to an increase in the membrane permeability, which in turn leads to 'permeation' of intracellular materials and leakage of potassium ions $(\mathrm{K}+)^{36}$. The presence of these elements, namely $\mathrm{N}, \mathrm{P}$ and $\mathrm{S}$ from proteins could thus be inferred that silver has a high affinity for these heteroatoms ${ }^{37}$. The nanoparticles cause severe damage to the cell wall and plasma membrane of bacterial cell through peroxidation of lipids in the membrane. The mechanism of action of silver is linked with its interaction with thiol group compounds found in the respiratory enzymes of bacterial cells. Silver binds to the bacterial cell wall and cell membrane and inhibits the respiration process and protein inactivation. These effects eventually compromise the wall and plasma membrane structural integrity, deregulating transport and leading to $\mathrm{K}+$ leakage $^{38}$. The silver nanoparticles show efficient antimicrobial property compared to other salts due to their extremely large surface area, which provides better contact with microorganisms. The nanoparticles get attached to the cell membrane and also penetrate inside the bacteria. The bacterial membrane contains sulfur-containing proteins and the silver nanoparticles interact with these proteins in the cell as well as with the phosphorus containing compounds like DNA. When silver nanoparticles enter the bacterial cell it forms a low molecular weight region in the center of the bacteria to which the bacteria conglomerates thus, protecting the DNA from the silver ions. The nanoparticles preferably attack the respiratory chain, cell division finally leading to cell death. The nanoparticles release silver ions in the bacterial cells, which enhance their bactericidal activity ${ }^{37}$. The ability of silver nanoparticles to destroy fungal cell electric potential and membrane function also has been already well documented. Silver nanoparticles break down the membrane permeability barrier by acting on ergosterol in the fungal lipid bilayer causing the leakage of ions and other materials forming pores and dissipating the electrical potential of the membrane which finally leads to cell death ${ }^{39}$.

\section{CONCLUSION}

The novel technologies, especially those employing nanotechnology, have paved way for the development of improved personal hygiene products. The use of such products could minimize the impact of poor cleaning, disinfecting practices in household and most importantly nosocomial infections. Thus, the biogenic silver nanoparticles proved to be a promising antibacterial and antifungal additive to commercially available hand wash and dish wash for an enhanced antibacterial and antifungal performance against pathogenic strains.

\section{ACKNOWLEDGEMENT}

We would like to thank Dr. R. Kirubagaran, Scientist F, Group head, Marine Biotechnology, National Institute of Ocean Technology, Chennai and Dr. K. Gopalakrishnan Member, Board of Governors, National Design and Research Forum, Bangalore, India for providing instrumentation facility. We would also like to thank Prof. R. Rengasamy, Director, CAS in Botany, Univesity of Madras, Guindy campus for providing lab facilities.

\section{REFERENCES}

1. Goffeau A. Drug resistance: the fight against fungi. Nature 2008; 452: 541-542. http://dx.doi.org/10.1038/452541a PMid:18385723

2. Williams DH, Bardsley B. The vancomycin group of antibiotics and the fight against resistant bacteria. Angew. Chem. Int. Ed 1999; 38: $1172-$ 1193.http://dx.doi.org/10.1002/(SICI)1521-3773(19990503)38:9< 1172::AID-ANIE1 172>3.0.CO;2-C

3. Goldmann DA, Weinstein RA, Wenzel RP, Tablan OC, Duma RJ, Gaynes RP, Schlosser J, Martone WJ. Strategies to prevent and control the emergence and spread of antimicrobial-resistant microorganisms in hospital. A challenge to hospital leadership. JAMA 1996; 275: 234-240. http://dx.doi.org/10.1001/jama.275.3.234 http://dx.doi.org/10.1001/jama.1996.03530270074035 PMid:8604178

4. Chastre J. Evolving problems with resistant pathogens. Clin. Microbiol.Infect 2008; 14: 3-14. http://dx.doi.org/10.1111/j.14690691.2008.01958.x PMid:18318874

5. Salata OV. Applications of nanoparticles in biology and medicine. Journal of Nanobiotechnology 2004; 2: 1-6. http://dx.doi.org/ 10.1186/1477-3155-2-3 http://dx.doi.org/10.1186/1477-3155-2-1 PMid:14715086 PMCid:PMC324569

6. Bosetti M, Masse A, Tobin E, Cannas M. Silver coated materials for external fixation devices: in vitro biocompatibility and genotoxicity. Biomaterials 2002; 23(3): 887-892. http://dx.doi.org/10.1016/S01429612(01)00198-3

7. Cho M, Chung H, Choi W, Yoon J. Different inactivation behaviors of MS-2 phage and Escherichia coli in $\mathrm{TiO}_{2}$ photocatalytic disinfection. Appl. Environ. Microbiol 2005; 71(1): 270-275. http://dx.doi.org /10.1128/AEM.71.1.270-275.2005 PMid:15640197 PMCid:PMC544209

8. Cho KH, Park JE, Osaka T, Park SG. The study of antimicrobial activity and preservative effects of nanosilver ingredient. Electrochimica Acta 2005; 51: 956-960. http://dx.doi.org/10.1016/j.electacta.2005.04.071 
9. Jonathan CR, Amanda JH, Adam DM, Chanda RY, Richard PVD. A nanoscale optical biosensor: Real-time immunoassay in physiological buffer enabled by improved nanoparticle adhesion. Journal of Physical Chemistry B 2003; 107: 1772-1780. http://dx.doi.org/10.1021 /jp022130v

10. Tien D, Tseng K, Liao C, Tsung T. Identification and quantification of ionic silver from colloidal silver prepared by electric spark discharge system and its antimicrobial potency study. Journal of Alloys and Compounds 2009; 473: 298-302. http://dx.doi.org/10.1016 j.jallcom.2008.05.063

11. Inoue $\mathrm{Y}$, Hoshino M, Takahashi H, Noguchi T, Murata T, Kanzaki $Y$, Hamashima H, Sasatsu M. Bactericidal activity of Ag-zeolite mediated by reactive oxygen species under aerated conditions. Journal of Inorganic Biochemistry 2002; 92: 37-42. http://dx.doi.org/10.1016 /S0162-0134(02)00489-0

12. Totaro P, Rambaldini M. Efficacy of antimicrobial activity of slow release silver nanoparticles dressing in post-cardiac surgery mediastinitis. Interactive Cardiovascular and Thoracic Surgery 2009; 8: 153-154. http://dx.doi.org/10.1510/icvts.2008.188870 PMid:18948308

13. Lee PC, Meisel D. Adsorption and Surface-Enhanced Raman of Dyes on Silver and Gold Sols. J. Phys. Chem 1982; 86: 3391-3395. http://dx.doi.org/10.1021/j100214a025

14. Liu YC, Lin LH. New pathway for the synthesis of ultrafine silver nanoparticles from bulk silver substrates in aqueous solutions by sonoelectrochemical methods. Electrochem. Commun 2004; 6: 11631168. http://dx.doi.org/10.1016/j.elecom.2004.09.010

15. Mallick K, Witcombb MJ, Scurrella MS. Self-assembly of silver nanoparticles in a polymer solvent: Formation of a nanochain through nanoscale soldering. Mater Chem. Phys 2005; 90: 221-224. http://dx.doi.org/10.1016/j.matchemphys.2004.10.030

16. Morones JR, Elechiguerra JL, Camacho A, Ramirez JT. The bactericidal effect of silver nanoparticles. Nanotechnology 2005; 16: 2346-2353. http://dx.doi.org/10.1088/0957-4484/16/10/059 PMid:20818017

17. Manjumeena R, Girilal M, Mageshpeter, Kalaichelvan PT. Augmenting potential antifungal activity of Gandhaka Rasayana (a siddha compound) using green synthesized silver nanoparticles from couroupita guianensis leaf extract against selected pathogenic strains. Int. Res. J. Pharm 2013; 4(6): 234-239. http://dx.doi.org/10.7897/2230-8407.04653

18. Ghoreishi SM, Behpour M, Khayatkashani M. Green synthesis of silver and gold nanoparticles using Rosa damascena and its primary application in electrochemistry. Physica E 2011; 44: 97-104. http://dx .doi.org/10.1016/j.physe.2011.07.008

19. Dubey SP, Lahtinen M, Silla M. Green synthesis and characterizations of silver and gold nanoparticles using leaf extract of Rosa rugosa. Colloids and Surf. B: Biointerfaces 2010; 64: 34-41.

20. Fayaz AM, Girilal M, Rahman M, Venkatesan R, Kalaichelvan PT. Biosynthesis of silver and gold nanoparticles using thermophilic bacterium Geobacillus stearothermophilus. Process Biochem 2011; 46: 1958-1962. http://dx.doi.org/10.1016/j.procbio.2011.07.003

21. Fayaz AM, Tiwary CS, Kalaichelvan PT, Venkatesan R. Blue orange light emission from biogenic synthesized silver nanoparticles using Trichoderma viride. Colloids and Surf. B: Biointerfaces 2010; 75: 175178. http://dx.doi.org/10.1016/j.colsurfb.2009.08.028 PMid:19783414

22. Kowshik M, Ashtaputre S, Kharrazi S, Vogel W, Urban J, Kulkarni SK, Paknikar KM. Extracellular synthesis of silver nanoparticles by a silvertolerant yeast strain MKY3. Nanotechnology 2003; 14: 95-100. http://dx.doi.org/10.1088/0957-4484/14/1/321

23. Kalishwaralal K, Deepak V, Ram Kumar Pandian S, Kottaisamy M, Barathmani KS, Kartikeyan B, Gurunathan S. Biosynthesis of silver and gold nanoparticles using Brevibacterium casei. Colloids Surf. B: Biointerfaces 2010; 77: 257- 262. http://dx.doi.org/10.1016/ j.colsurfb.2010.02.007 PMid:20197229

24. Shankar SS, Ahmad A, Sastry M. Geranium leaf assisted biosynthesis of silver nanoparticles. Biotechnol. Prog 2003; 19: 1627-1631. http://dx.doi.org/10.1021/bp034070w PMid:14656132
25. Jones SA, Bowler PG, Walker M, Parsons D. Controlling wound bioburden with a novel silver containing hydrofiber dressing. Wound Repair Regen 2004; 12: 288-94. http://dx.doi.org/10.1111/j.10671927.2004.012304.x PMid:15225207

26. Hochmannova L, Vytrasova J. Photocatalytic and antimicrobial effects of interior paints. Progress in Organic Coatings 2010; 67: 1-5. http://dx.doi.org/10.1016/j.porgcoat.2009.09.016

27. Shrivastava S, Tanmay BE, Roy A, Singh G, Ramachandra RP, Dash D. Characterization of enhanced antibacterial effects of novel silver nanoparticles. Nanotechnolgy 2007; 18: 225103. http://dx.doi.org/ $10.1088 / 0957-4484 / 18 / 22 / 225103$

28. Mulvaney P. Surface plasmon spectroscopy of nanosized metal particles. Langmuir 1996; 12: 788-800. http://dx.doi.org/10.1021/la9502711

29. Noginov MA, Zhu G, Bahoura M, Adegoke J, Small C, Ritzo BA, Drachev VP, Shalaev VM. The effect of gain and absorption on surface plasmons in metal nanoparticles. Appl. Phys. B 2007; 86: 455-460. http://dx.doi.org/10.1007/s00340-006-2401-0

30. Prathna TC, Chandrasekaran N, Raichur MA, Mukherjee A. Biomimetic synthesis of silver nanoparticles by Citrus limon (lemon) aqueous extract and theoretical prediction of particle size. Colloids Surf. B 2011; 82: $\quad 152-159$. http://dx.doi.org/10.1016/j.colsurfb.2010.08.036 PMid:20833002

31. Caruso F, Furlong DN, Ariga K, Ichinose I, Kunitake T. Characterization of polyelectrolyte-protein multilayer films by atomic force microscopy, scanning electron microscopy and Fourier transform infrared reflection-absorption spectroscopy. Langmuir 1998; 14: 45594565. http://dx.doi.org/10.1021/la971288h

32. Macdonald IDG, Smith WE. Orientation of Cytochrome $c$ adsorbed on a citrate-reduced silver colloid surface. Langmuir 1996; 12: 706-13. http://dx.doi.org/10.1021/la950256w

33. Mitrikas G, Deligiannakis Y, Trapalis CC, Boukos N, Kordas G. CW and Pulsed EPR Study of Silver Nanoparticles in a $\mathrm{SiO}_{2}$ Matrix. J. SolGel Sci. Technol 1998; 13: 503-508. http://dx.doi.org/10.1023 /A: 1008654102264

34. Kim KJ, Sun WS, Suh BK, Moon SK, Choi JS, Kim JG, Lee DG. Antifungal activity and mode of action of silver nanoparticles on Candida albicans. Biometals 2009; 22: 235-242. http://dx.doi.org /10.1007/s10534-008-9159-2 PMid:18769871

35. Dorau B, Arango R, Green F. Proceedings of the $2^{\text {nd }}$ Wood-Frame Housing Durability and Disaster Issues Conference, Forest Products Society, Las Vegas, NV 2004; 4-6: 133-145.

36. Yamanaka M, Hara K, Kudo J. Bactericidal actions of a silver ion solution on Escherichia coli, studied by energy-filtering transmission electron microscopy and proteomic analysis. Appl. Environ. Microbiol 2005; 71: 7589-7593. http://dx.doi.org/10.1128/AEM.71.11.75897593.2005 PMid:16269810 PMCid:PMC1287701

37. Feng QL, Wu J, Chen GQ, Cui FZ, Kim TN, Kim JO. A mechanistic study of the antibacterial effect of silver ions Escherichia coli and Staphylococcus aureus. Biomed J. Biomed Mater 2000; 52: 662-8. http://dx.doi.org/10.1002/1097-4636(20001215)52:4<662::AIDJBM10>3.0.CO;2-3

38. Karthik C, Rafael PB, Zhiping L, Sajid B, Jingbo L. Comparison of bactericidal activities of silver nanoparticles with common chemical disinfectants. Colloids and Surfaces B: Biointerfaces 2011; 84: 88-96. http://dx.doi.org/10.1016/j.colsurfb.2010.12.020 PMid:21227664

39. Kim K, Woo SS, Bo KS, Seok Ki M, Jong Soo C, Jong GK, Dong GL. Antifungal activity and mode of action of silver nanoparticles on Candida albicans. Biometals 2009; 22: 235-242. http://dx.doi.org/ 10.1007/s10534-008-9159-2 PMid:18769871

\section{Cite this article as:}

Manjumeena Rajarathinam, P. T. Kalaichelvan. Biogenic nanosilver as a potential antibacterial and antifungal additive to commercially available dish wash and hand wash for an enhanced antibacterial and antifungal activity against selected pathogenic strains. Int. Res. J. Pharm. 2013; 4(7): 68-75 http://dx.doi.org/10.7897/2230-8407.04715 